\title{
Trayectorias laborales y redes sociales de nuevos inmigrantes chinos residentes en México
}

Chinese newcomer immigrants in Mexico:

career paths and social networks

\author{
Luz Helena Rodríguez Tapia* ISSN IMPRESO 1870-7599 | ISSN RED CÓMPUTO 2448-7783 | 83-105 \\ María Eugenia Anguiano Téllez** \\ RECIBIDO 06/02/19 | ACEPTADO 14/04/19
}

Resumen. En décadas recientes, el panorama migratorio de China en su interior y su exterior, se ha transformado notablemente. Hacia el exterior, una nueva oleada de trabajadores está emigrando hacia diversos países del mundo, entre ellos México. Se analizan tres modalidades de inserción laboral de un conjunto de inmigrantes chinos que han llegado a México en el presente siglo XXI, se destaca la relevancia de sus redes sociales, a partir de información obtenida mediante entrevistas semiestructuradas y utilizando el enfoque de trayectoria laboral.

Palabras clave: inmigrantes chinos, trayectorias laborales, redes sociales.

Abstract. China's migration context has changed in recent decades. A new wave of international emigrants, mostly workers, settled in various countries around the world, including Mexico. This paper analyzes the labor career paths and the social networks of Chinese immigrants who have arrived to Mexico during the 21st century, employing the work career approach and based on interview data.

Keywords: chinese immigrants, labor career path, social networks.

\footnotetext{
* Mexicana. Maestra en Estudios de Población por el Colegio de la Frontera Norte, docente en el Posgrado en Antropología de la Universidad Nacional Autónoma de México Correo-e: luz.helena.rta@gmail.com

${ }^{* *}$ Mexicana. Doctora en Ciencia Social con especialidad en Sociología por El Colegio de México; profesora e investigadora titular en El Colegio de la Frontera Norte, adscrita al Sistema Nacional de Investigadores. Correo-e: anguiano@colef.mx
} 


\section{Introducción ${ }^{1}$}

En el marco del Socialismo con características chinas, de Deng Xiaoping, y como resultado de diversas reformas instauradas en el país a partir de 1979, China transitó de una economía socialista a una economía de mercado, a raíz de ello experimentó un acelerado proceso de industrialización que la condujo a posicionarse como la «fábrica del mundo» (Izraelewicz, 2005). Paralelamente a la apertura al exterior y a la expansión económica, se incrementaron los flujos de productos, bienes y capitales, así como el movimiento de personas dentro y fuera de ese país asiático.

Del moderno y nuevo proyecto nacional chino de la década de 1980 se derivó la flexibilización de la política migratoria que hizo más accesible desplazarse en el interior del territorio y también hacia el extranjero (Pal Nyiri, 2002). ${ }^{2}$ Según Xiang Biao (2003), el hecho de que la República Popular postmaoísta facilitara la emigración de sus ciudadanos se encuentra vinculado a la estrategia de desarrollo de China, donde el objetivo último era construir una comunidad transnacional globalizada, que continuara ampliando sus conexiones e influencia regional y posibilitara de ese modo la integración de China en el mundo. ${ }^{3}$

En este nuevo contexto, las corrientes migratorias de chinos al exterior $-\mathrm{y}$ al continente americano, en particular - se reactivaron, entre ellas la que está llegando a territorio mexicano. Con el objetivo de explorar la inserción laboral de los inmigrantes chinos a ese país en años recientes, se analiza información obtenida a través de un conjunto de entrevistas semiestructuradas a inmigrantes chinos que han residido en el país. Dichas entrevistas se realizaron entre los años 2015 y 2018, y se centraron en las experiencias migratorias, ocupacionales y comunitarias de los informantes, se enfocaron en las características de su actividad laboral, y en los vínculos (redes sociales) establecidos con familiares, amigos,

\footnotetext{
${ }^{1}$ Esta investigación recibió financiamiento del Fondo de Investigación Científica Básica 2012 del Conacyt, Proyecto 0178078: Flujos migratorios en las fronteras norte y sur de México y en tránsito hacia Estados Unidos: dinámicas poblacionales y políticas migratorias, coordinado por María Eugenia Anguiano Téllez, profesora investigadora de El Colegio de la Frontera Norte.

${ }^{2}$ Durante el periodo maoísta, los desplazamientos migratorios fueron controlados severamente y la emigración al exterior fue, incluso, considerada como "traición a la patria» (Portes y Min Zhou, 2013).

${ }^{3}$ En el siglo XXI, la posición de China como potencia mundial se ha desarrollado a partir de un sistema eficiente de conexiones globales y de transformaciones que responden a varios intereses económicos, principalmente capitalistas. La extensión de las fronteras chinas y su influencia global se armonizaron con el reajuste geopolítico y económico en el mundo (Tébar, 2013).
} 
paisanos y con la propia organización laboral. La elección de los casos se dio por la diversidad que representaron, aunque coincidieron en que la localidad de ingreso fue la ciudad fronteriza de Tijuana, Baja California, ubicada al noroeste del país y vecina de San Diego, California.

El artículo se organiza en tres secciones: en la primera se presenta el contexto de la inmigración china en México, en la segunda se postula la relevancia de referirse a los inmigrantes chinos recientes o nuevos inmigrantes chinos residentes en México, la tercera examina tres casos seleccionados que permiten caracterizar diferentes trayectorias laborales e identificar distintos tipos de redes sociales creadas para apoyar los procesos de inserción laboral.

\section{La inmigración china en México}

La inmigración china en México no es un fenómeno de reciente aparición. ${ }^{4}$ A finales del siglo XIX y durante las primeras décadas del siglo XX, la situación nacional en China y las particularidades del contexto receptor latinoamericano propiciaron una corriente migratoria con rasgos específicos.

Durante el siglo XIX, China vivió una fuerte crisis socioeconómica y política relacionada con múltiples factores: crecimiento poblacional, insuficiencia alimentaria, intervenciones extranjeras, pobreza extrema y algunos desastres naturales. Los gobiernos de la época estimularon las corrientes al exterior para descargar la sobrepoblación y mejorar la balanza económica mediante las remesas y la exportación de productos (Martínez y Reynoso, 1993). La mayoría de los emigrantes internacionales chinos de aquellos años fueron contratados en sus localidades de origen y tuvieron por destino el continente americano: Estados Unidos, Perú y Cuba, principalmente. A estos trabajadores migrantes de ultramar se les conoció con el nombre de coolies o culíes.

En México, durante el régimen de Porfirio Díaz en la década de 1890, se permitió la llegada masiva de trabajadores extranjeros, entre ellos los culíes. El arribo de estos trabajadores tuvo la finalidad de solventar la insuficiencia de mano de obra existente en ciertas regiones del país y en actividades primordiales para el proyecto modernizador nacional, como la construcción de ferrocarriles, la

${ }^{4}$ Si bien la presencia de población china en el territorio mexicano puede remontarse a la época de la colonización española en América, en este trabajo interesa referirse solamente a la época más reciente. 
explotación minera y el desarrollo agrícola. En aquellos años, la firma de un convenio comercial para introducir trabajadores chinos, propiciaría un flujo significativo de inmigrantes procedentes de ese país. La mayoría provino de Guangdong (Cantón), aunque también los había originarios de Hong Kong y Amoy (Cardiel, 1997).

A finales del siglo XIX, otro significativo flujo de inmigrantes chinos llegó a México procedente desde Estados Unidos debido a la Ley de Exclusión China de 1882 (Chinese Exclusion Act), que les llevó a moverse al sur de la frontera estadounidense con la esperanza de retornar algún día a ese país; sin embargo, con el paso del tiempo fueron asentándose en México.

La población de chinos de aquel tiempo estuvo conformada mayoritariamente por hombres jóvenes en edades laborales que se movieron apoyados por redes de parentesco y paisanaje (Ham, 1997). De este periodo datan las comunidades, los barrios chinos, las cafeterías y los restaurantes emblemáticos de ciudades como Mexicali, en Baja California y la Ciudad de México.

Para la segunda mitad del siglo XX, la inmigración china hacia México fue mermando notablemente (Salazar, 1996). Dos hechos dieron pauta para inhibirla: por un lado, el territorio mexicano se había convertido en un destino hostil para los inmigrantes chinos; ${ }^{5}$ por el otro, en el país asiático, se instauró la República Popular de China con un régimen que controló severamente la movilidad territorial de sus ciudadanos. ${ }^{6}$

En los albores del siglo XXI, se ha registrado un aumento significativo de la inmigración china en México. De acuerdo con información censal, en sólo 15 años la población de inmigrantes chinos se quintuplicó. El Censo de Población y Vivienda del año 2000 registró mil,754 residentes nacidos en China en el país; tres quinquenios más tarde la Encuesta Intercensal 2015 captó 8 mil 860 personas nacidas en China residiendo en México. De estas últimas, 5 mil,371 (60.6 por ciento) eran hombres y 3 mil 489 mujeres (39.4 por ciento), y sus edades oscilaron mayoritariamente entre los 20 y los 44 años (63.6 por ciento), por lo que se trataba

\footnotetext{
${ }^{5}$ Esta etapa de inmigración china en México estuvo marcada constantemente por el rechazo, la xenofobia y el racismo de la sociedad mexicana, una sociedad que puso al mestizaje indio-europeo como la base de su identificación nacionalista y, además, se alimentó del imaginario social negativo que existía internacionalmente en torno a la población china (Anguiano, 2010).

${ }^{6}$ Durante el periodo maoísta, los desplazamientos hacia el exterior experimentaron un estricto control basado en la ideología estatal y las relaciones internacionales: La frontera «no era sólo un símbolo de soberanía, sino que también se percibía como una línea entre los mundos «socialista〉 y «capitalista» (Xiang, 2005:141).
} 
de personas que se encontraban en las etapas más activas de la vida productiva y reproductiva.

La Encuesta Intercensal permite también saber que la mayoría de esos inmigrantes se encontraba trabajando (72.5 por ciento), y en menor proporción se dedicaba a quehaceres del hogar, al estudio o eran jubilados o pensionados. El sector terciario concentró 95.2 por ciento del total de trabajadores, quienes se desempeñaban notoriamente en el ramo de los servicios (concretamente, restaurantes) y el comercio.

A diferencia del panorama de crisis socioeconómica y política que vivió China durante los siglos anteriores, o de la existencia de una política específica que promoviera la llegada masiva de trabajadores extranjeros (como sucedió durante el Porfiriato), para los nuevos inmigrantes chinos, la posición de México como país de atracción migratoria podría estar relacionada con la oportunidad de emplearse en nichos laborales muy específicos, donde el país receptor se revela como un destino estratégico por su cercanía a Estados Unidos y su conexión con la región de América Latina.

A su vez, considerando las transformaciones ocurridas en China bajo el contexto de la globalización de finales del siglo XX y principios del siglo XXI, la inserción laboral de los inmigrantes chinos recientes podría estar asociada con la organización y las redes laborales, comerciales, empresariales o profesionales que la comunidad china ha venido construyendo, en tanto el colectivo inmigrante se convierte en un espacio social compartido que facilita la adaptación y propicia la unificación, y posiblemente se convierte también en un proveedor de oportunidades laborales.

Estas dos hipótesis de trabajo guiaron la investigación: por una parte, la posición estratégica de México como contexto receptor, posiblemente así percibida por una nueva oleada de inmigrantes chinos y, por otra, la preeminencia del apoyo que las redes sociales ofrecen a los recién llegados.

\section{Los emigrantes chinos recientes en México}

La inserción proactiva de China en la economía global y la flexibilización de su política migratoria hacia el exterior, han dinamizado los procesos de movilidad de la población que emigra hacia el extranjero en busca de empleos o estudios profesionales considerados mejores o más competitivos, hecho que ha 
propiciado la intensificación y diversificación de los flujos migratorios chinos contemporáneos.

El cambio de política económica y la proyección como futura potencia favorecieron que los vínculos de China con el exterior se extendieran, incluso hacia sus propios ciudadanos emigrantes (Beltrán, 2004). Este giro hacia la reconexión con la diáspora comenzó en la década de 1980, cuando el gobierno chino promulgó leyes y creó una política migratoria que permitió una mejor intervención en las salidas y el mantenimiento de vínculos con los chinos residentes en el extranjero. Guofu Liu (2009) divide el proceso de mayor reformulación migratoria en tres etapas:

1. De 1979 a 1985 cuando se iniciaron las reformas al marco de la migración restrictiva a través de la promulgación de la Ley de Migración que dio reconocimiento legal al derecho del ciudadano chino a irse y regresar.

2. De 1986 a 2001 cuando se desarrolló un nuevo marco regulatorio que suprimía varias restricciones a los ciudadanos chinos que emigraban, se alentó el retorno y se establecieron agencias intermediarias de migración.

3. Posterior a 2001, etapa que se inauguró con el ingreso de China a la Organización Mundial del Comercio (OMC), en la cual se aplican nuevas reformas a la administración de salidas y entradas, agilizando la solicitud de pasaportes y suprimiendo las restricciones para viajar a Hong Kong y Macao.

La nueva generación de viajeros internacionales comenzó a ser categorizada como los «nuevos migrantes», conformados por personas que salieron de China tras la apertura económica. Este conjunto de emigrantes, surgido en el contexto del éxito económico y de los procesos de globalización, personifica esencialmente la creación de nodos de contacto en la China global:

Una gran parte de estos nuevos migrantes son bien educados o comerciantes. Con la integración progresiva de China en la economía mundial, las remesas y las inversiones de los viejos emigrantes perdieron importancia; en contraste, los intercambios internacionales en los sectores de alta tecnología y la expansión de los mercados internacionales de las empresas chinas se convirtieron en una nueva prioridad (Xiang, 2003:27, traducción propia).

De acuerdo con Liu (2005), a los nuevos emigrantes se les suele clasificar en cuatro tipos de perfiles: estudiantes prolongados, migrantes en cadena, emigrantes 
trabajadores o profesionales con permiso (normalmente calificados), e inmigrantes indocumentados.

La inserción de los nuevos migrantes chinos en las comunidades del exterior va a ser facilitada por fuertes redes que están produciendo nuevas formas de organización migratoria (Nieto, 2007). Adicionalmente, un mercado de servicios que funciona como intermediario de la migración, conformado por agencias (establecidas formal o informalmente), ayuda a los emigrantes a conseguir visa, transporte y empleo. Estos agentes y agencias forman parte de la llamada industria de la migración (Xiang, 2005), que ha sido propensa a extenderse como resultado del surgimiento de un mercado laboral muy flexible, a veces informal, y particularmente en sectores intensivos ubicados en países desarrollados (Xiang, 2010).

Las transformaciones político-económicas de China y la intensificación reciente de los flujos migratorios internacionales se conjugaron para alentar la salida hacia múltiples destinos. Dentro de los países de recepción de estos nuevos emigrantes se encuentra México. La presencia numérica de esta población puede examinarse mediante las estadísticas y los registros oficiales de inmigración que documentan las instancias gubernamentales dedicadas a ello en México.

Durante los tres últimos lustros, el grupo de población categorizado censalmente como "nacidos en China» ha mostrado una tendencia de crecimiento positivo. Si se hace una revisión de las cifras de inmigrantes chinos registrados en los Censos de Población, así como en la última Encuesta Intercensal, se corrobora un crecimiento numérico paulatino en los pocos años transcurridos del siglo XXI.

Al analizar la información de la gráfica 1, se observa que entre los años 2000 y 2010, la población china residente en México se incrementó de mil,754 a 6 mil 655 personas, por lo que experimentó una tasa de crecimiento de 14.3 por ciento (Castillo, 2012). La información intercensal del 2015 muestra que la cifra continuó aumentando, con un registro de 8 mil,860 inmigrantes chinos. En los mismos registros se aprecia una mayor presencia masculina. 


\section{GRÁFICA 1}

Volumen de la población china residente en México, 2000-2015

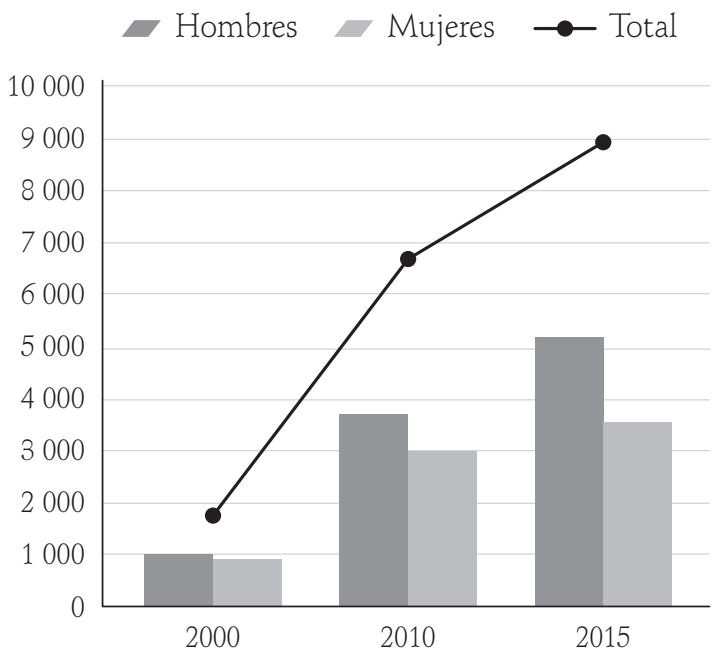

Fuente: elaboración propia con base en los datos del Censo de Población y Vivienda 2000, el Censo de Población y Vivienda 2010, y la Encuesta Intercensal 2015, INEGI.

\section{0}

Para referirse propiamente a los nuevos inmigrantes chinos, considerando como tales a quienes han ingresado en años recientes a México, es posible utilizar las estadísticas que proporcionan los Registros Administrativos, consignados por el Instituto Nacional de Migración (INM).

Con base en esa información, y teniendo en cuenta el número de tarjetas de residencia emitidas anualmente bajo las formas de «Residente permanente» o de

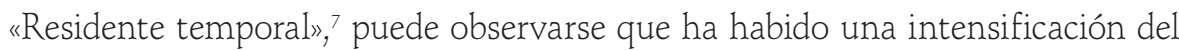
flujo inmigratorio chino, pues como se muestra en la gráfica 2, entre los años 2010 a 2017 se otorgaron anualmente más de 2 mil 800 documentos migratorios a personas con nacionalidad china. Los mismos registros permiten apreciar que el trabajo es un motivo sobresaliente asociado al permiso de inmigración; lo que sugiere que la migración de los chinos, que recientemente han llegado a México, se relaciona con cuestiones de trabajo.

7 Un aspecto a considerar es que en la nueva Ley de Migración del año 2011, la calidad de «No inmigrante», «Inmigrante» eInmigrado» se suprimieron, estableciéndose dos categorías más amplias: «Residentes temporales» $y$ "Residentes permanentes». Esto tiene consecuencias en la homologación de las categorías y la comparación histórica de los datos del registro, particularmente después del año 2013, cuando entró en vigor el Reglamento de dicha ley. 


\section{GRÁFICA 2}

Número de tarjetas de residencia otorgadas a chinos por el INM, 2010-2017

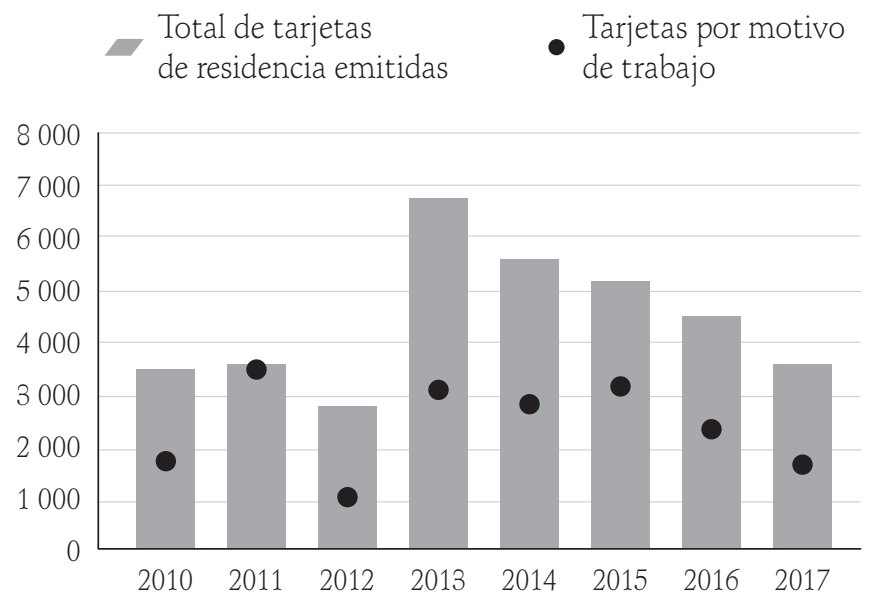

Fuente: elaboración propia con base en los datos de los Registros Administrativos, INM.

En síntesis, la información estadística registrada en los dos últimos Censos, la Encuesta Intercensal 2015 y los Registros Administrativos del INM indican que ha ocurrido un incremento significativo de los flujos de inmigración y del número de residentes chinos en México, se observa que la mayoría ha llegado por motivos laborales.

\section{Redes sociales, inserción ocupacional y trayectorias laborales}

Sobre la inmigración china en México existe una amplia bibliografía histórica centrada en el periodo de 1882 a 1930, dada la relevancia del flujo migratorio de esa época (Hu-Dehart, 2004; Xu Shicheng, 2007; Zlotnik, 1991; Gómez, 1991; Cardiel, 1997; Puig, 1992; Velázquez, 2008; Cinco, 2012, entre otros). Adicionalmente, los estudios suelen referirse a temas vinculados con la discriminación, el racismo y la xenofobia. En contraste, la fase actual y los procesos de inserción laboral han sido menos estudiados, a pesar de que la "cuestión migratoria china» adquiere relevancia por el incremento del flujo migratorio y la presencia cada vez mayor de inmigrantes chinos residentes en México. 
La migración china en otros países del mundo (principalmente la localizada en Europa, Norteamérica y África) ha sido abordada a partir de conceptos como diáspora, transnacionalismo y chinos de ultramar, por autores como Wang Gungwu (1991), Pieke (2006), Ma y Cartier (2003), Pan (1999), Trolliet (1994), Ma Mung (2000), entre otros. Referirse a la inserción laboral en el país de destino, exhorta a realizar una revisión desde otras perspectivas analíticas.

En los estudios de migración existen aproximaciones teóricas y metodológicas que se centran en la integración económica de los sujetos en las sociedades receptoras, también hay las que indagan sobre las razones de la continuidad de los procesos migratorios. Estas perspectivas pueden proporcionar un primer acercamiento para entender la inserción laboral de los inmigrantes.

Considerando que el interés principal de este trabajo fue indagar sobre la manera en que los inmigrantes (chinos) recientes se insertan laboralmente en un lugar de destino (México), se consideró que los enfoques de «redes sociales» y «trayectorias laborales» eran perspectivas conceptuales apropiadas para orientar la investigación.

La perspectiva de las redes sociales permite valorary analizar los lazos sociales que conectan a las personas del mismo origen en el lugar de destino. Esas redes se entienden como «conjuntos de relaciones interpersonales que vinculan a los inmigrantes (...) con parientes, amigos o compatriotas, ya sea en el país de origen o en el de destino» (Arango, 2003:19). Con relación al mercado de trabajo, las redes sociales representan un elemento esencial, pues cumplen la función de facilitar la obtención de empleo, proporcionan contactos y recursos económicos, y otro tipo de apoyos durante el proceso de inserción en el país receptor, además de reducir las barreras socioculturales, del idioma y de la revalidación escolar o profesional (Dombois, 1997). En consecuencia, resulta imprescindible referirse a las redes sociales porque para los inmigrantes (chinos) son determinantes en su situación laboral.

De los estudios sobre inmigración e integración económica surgió la línea de investigación sobre los nichos laborales, que centra su atención en observar cómo los inmigrantes de un mismo origen se concentran en un número limitado de ocupaciones o industrias formando «nichos» (Light, 1972; Waldinger, 1993; Kaplan y Li, 2006, entre otros). Las investigaciones sobre inmigrantes chinos y empleo se han alimentado de esta perspectiva y, principalmente, del concepto de enclave étnico que surge como un intento para categorizar las aglutinaciones de personas de origen extranjero en sociedades o localidades receptoras (Wilson y Portes, 1980; Sanders y Nee, 1987; Portes y Jensen, 1989; Min Zhou y Logan, 1989). 
De acuerdo con los principales exponentes de este concepto, el enclave va a definirse, en términos económicos y ocupacionales, como la concentración en un espacio físico (generalmente una zona metropolitana) de empresas étnicas que emplean una proporción significativa de trabajadores de la misma minoría o grupo étnico (Malgesini y Giménez, 2000).

No obstante, se cuestiona si la perspectiva del enclave étnico como facilitador u obstructor del proceso de incorporación laboral de los inmigrantes es suficiente para continuar analizando la inmigración china en los países receptores ya que, en la actualidad, la localización del enclave chino, al menos en México, ya no puede encontrarse únicamente en la forma del Chinatown o barrio chino.

Se suma el hecho de que los chinos ya no tejen redes migratorias basadas únicamente en el parentesco, sino que muchas veces son las empresas globales chinas las que contratan a reclutadores para hacerse de empleados coétnicos (explicado por la expansión económica de China y también por el hecho de que entre paisanos se comparte una misma cultura del trabajo). La migración china ha iniciado así un proceso de deslocalización territorial en las zonas de recepción, pero también de fortalecimiento de sus redes sociales vinculadas a los procesos globales.

El estudio de las migraciones chinas contemporáneas requiere fijar su atención en tres elementos: las redes sociales de los migrantes, sus características sociodemográficas (principalmente ocupacionales) y la organización laboral bajo el contexto de la globalización. En consecuencia, en la investigación se propuso utilizar un abordaje que pudiese dar cuenta del proceso de inserción laboral de los chinos residentes en México llegados en años recientes al país. Por ello, para este trabajo se propuso utilizar una herramienta teórico-metodológica que tiene su origen en la sociodemografía y los estudios de tipo longitudinal: la trayectoria laboral.

Los estudios longitudinales se han usado en diversas disciplinas dentro de las ciencias sociales; sin embargo, tuvieron su origen en la sociodemografía con investigaciones insertas en temáticas como la familia y la reproducción, y los mercados laborales y las organizaciones (Rivera, 2012; Farrall, 2008; Pacheco y Blanco, 2002). En México, las investigaciones pioneras desarrolladas bajo este enfoque fueron las de Balán, Browning y Jelín (1977), y de Muñoz, de Oliveira y Stern (1977). Sus estudios se caracterizaron por examinar agregados de individuos $y$, particularmente, por hacer referencia al papel de las redes (en su caso, familiares) para la adaptación de los inmigrantes en las ciudades, así como por haber 
dado cuenta de las características demográficas de los grupos y sus miembros como condicionantes de la participación y ocupación laboral.

Como afirma Acosta (2003), los estudios sociodemográficos sobre migración de corte longitudinal fueron un intento por relacionar distintos niveles de análisis y varias dimensiones de la actividad económica de los individuos. Además, estos trabajos tuvieron la firme intención de responder a la pregunta sobre cuáles eran los factores asociados a la ocurrencia de un evento a lo largo de un periodo y en la trayectoria vital de una persona (Holland, Thomson y Henderson, 2006).

El principal aporte de las investigaciones antes citadas (y de las que le siguieron) fue iniciar una discusión sobre el papel que juegan tanto las redes como la reproducción social (observadas a través de las «estrategias de supervivencia») en la reproducción de la fuerza de trabajo y entre los diferentes miembros de una unidad social.

En la actualidad, el análisis de las trayectorias laborales es un enfoque muy recurrido en los estudios sociodemográficos de la migración, pues tiene como objetivo recuperar el aspecto dinámico que caracteriza al fenómeno de la movilidad poblacional, además de encadenar eventos (como la ocupación o el desempleo) y transiciones (como el paso de un trabajo a otro o el cambio en la condición de actividad); aspectos que podrían ser compartidos entre los miembros de un grupo de inmigrantes (Gandini, 2015; Mancini, 2013).

Complementariamente, las investigaciones que hacen uso de las trayectorias laborales pueden focalizarse en el análisis de las posiciones que las personas van ocupando en su trabajo a lo largo de sus vidas, y que permite vincular una mirada micro-social con procesos de carácter más general, como puede ser el fenómeno migratorio (Castronuovo, 2015).

\section{Análisis de trayectorias y redes sociales de los inmigrantes chinos}

Para conocer de primera fuente la compleja realidad del proceso migratorio y laboral de los inmigrantes chinos que residen en México y que llegaron al país en años recientes, en las entrevistas realizadas con un grupo seleccionado de ellos, se indagó sobre tres aspectos relevantes: a) Las características demográficas del individuo (sexo, edad, escolaridad, estado civil, posición en el grupo familiar). b) Sus ocupaciones y transiciones laborales (número de trabajos, tiempo 
de permanencia en ellos, tipos de empleos). c) Las redes sociales más significativas al momento de conseguir empleo (familia, paisanos, amigos, conocidos, vecinos, empresa).

El periodo de la trayectoria laboral (y por tanto del recorte biográfico en la entrevista con los inmigrantes chinos recientes) tuvo como punto de partida la llegada a México y como recorte final el empleo actual. Para este trabajo, del conjunto de entrevistas realizadas se eligieron tres historias que permiten ejemplificar diferentes trayectorias laborales y tipos de redes que caracterizan la diversidad de los casos. ${ }^{8}$

Trayectoria migratoria y laboral tradicional con fuertes vínculos familiares

Luisa llegó a la ciudad de Tijuana en el año 2008. Antes de su llegada tenía información sobre aspectos básicos de México porque sus padres habían inmigrado unas décadas atrás. Ellos habían estado trabajando en restaurantes chinos en Baja California mientras ella se criaba con sus abuelos en Enping, Guangdong, lugar del que son originarios. Al «hacerse mayor» y concluir los estudios técnicos, los padres de Luisa consideraron que había llegado el momento propicio para jubilarse (pues piensan que ya han envejecido) y que correspondía a Luisa salir de China y trabajar en el extranjero.

Los trámites requeridos para la movilidad migratoria de Luisa estuvieron a cargo de sus padres, quienes ya tenían experiencia con la documentación necesaria para realizar la movilidad; además consideraron necesario dejarla instalada antes de su retorno a China. Ella aceptó emigrar porque considera que la situación laboral en su país es muy competida y los salarios muy bajos. Al igual que sus padres lo habían hecho, para Luisa resultaba familiar irse a vivir al extranjero durante la edad productiva para retornar en la vejez (en China los adultos mayores gozan de prestaciones sociales que en México son imposibles de alcanzar siendo un inmigrante chino):

Antes en la ciudad de Enping no podías ganar mucho dinero y aquí [en Tijuana] ganas más. Y luego yo quiero. Bueno mi papá mandar la foto y yo pienso que es

${ }^{8}$ Los nombres de los informantes han sido cambiados para preservar la identidad y privacidad de los entrevistados. 
muy bonito. Pero cuando llegué (...) iay no! (ríe). Bueno yo así pienso. [La gente regresa porque] Enping, mi ciudad, es muy chiquita, pero hay más servicios que aquí en Tijuana (...). Y aquí siempre se fue la agua, la luz. Pero está bien aquí, yo vivo aquí mucho tiempo... Pero hospital ocupa mucho dinero y mis papás tienen casa y salud allá (entrevista a Luisa, enero de 2018).

Cuando llegó a México, obtuvo empleo como mesera y ayudante en un restaurante de una persona conocida. En ese lugar tuvo su primera inmersión de lleno al idioma español y a «los mexicanos» gracias a su contacto directo con los comensales del establecimiento. Su círculo más cercano fue la comunidad china conformada por los amigos de sus padres y por los compañeros del trabajo.

Gracias a una amiga en común, posteriormente conoció a su esposo. Él es originario de la misma región en China y se ha empleado en el mismo sector laboral que ella en México, ya que siempre ha trabajado en restaurantes chinos como cocinero. Una vez unida conyugalmente, Luisa se embarazó al poco tiempo, por lo que decidió suspender su trabajo durante un año y dedicarse por completo a la maternidad. Como ocurre en la tradición de una buena parte de las mujeres trabajadoras chinas, una vez que el bebé crece, es enviado a China con sus abuelos hasta que tenga la edad suficiente para cuidarse solo o haya aprendido el idioma chino con soltura:

Cuando mi bebé como seis o siete meses, mandé a mi hijo para China y mamá-papá me ayuda a cuidar. Entonces yo trabajo aquí (...) [Ahora] Tiene ocho años, ya está grande (...) Hablo con él cada semana con internet. Porque lunes a viernes mi hijo ir a la escuela, no hay tiempo (...) [Lo envié a China] porque mí quiero trabajo. Si hay trabajo, no hay gente o no hay familia que pueda cuidar mi hijo o en mi casa alguien para que yo me pueda ir al trabajo. Si quiero trabajo entonces mi hijo tengo que mandarlo (...) Ahorita un año o dos más y regreso para traer a mi hijo aquí para la escuela primaria. Quería antes, pero mi esposo dijo que mejor uno o dos años para que mi hijo pueda estudiar más chino allá (Entrevista a Luisa, enero de 2018).

En la actualidad, Luisa trabaja como cajera en un restaurante de comida china que tiene bastante éxito en Tijuana. Este trabajo lo consiguió hace seis años gracias a una oferta laboral que vio publicada en una de las redes sociales que sostiene el grupo étnico en internet (principalmente los grupos de «chinos en México» se comunican de manera virtual por QQ y WeChat). Luisa fue directamente a 
solicitar el empleo con la persona que sigue siendo su jefa, quien le dio trabajo inmediatamente:

¿Cómo conseguí? Antes, hace como siete años usábamos QQ y ahí teníamos unos grupos de Tijuana. Si algún restaurante ocupa o solicitan algo van a salir en el QQ del grupo. Ahorita tenemos WeChat de grupos de México. Ahí hay muchas cosas. Si quiere solicitar algo, vender algo, rentar algo, todo tiene (durante la entrevista, muestra en su teléfono celular los grupos a los que pertenece). Es como Facebook... Sí, solicitar gente y tenía que saber español... Me enteré por internet. [Pregunté:] ¿Ustedes solicitar cajera? Sí. Luego vine a trabajar (entrevista a Luisa, enero de 2018).

A sus 32 años, Luisa tiene planeado quedarse en México un tiempo considerable todavía y no ve su regreso a China como algo inminente. Sólo está a la espera de poder reunificarse con su hijo y que éste ingrese a la comunidad de chinos en Tijuana, como lo hizo ella y lo han hecho previamente otros inmigrantes chinos.

El caso de Luisa nos ilustra sobre un tipo de trayectoria migratoria y laboral de corte tradicional, en que las redes familiares y de paisanaje tienen un papel fundamental, y el nicho laboral étnico que gira en torno a los servicios de alimentación en restaurantes de comida china es el espacio de trabajo que permite la reproducción de la cadena migratoria; aunque en la actualidad apoyada por nuevos y modernos recursos virtuales establecidos gracias a internet y a la telefonía móvil.

Trayectoria migratoria y laboral reconfiguradas

con redes sociales en expansión

Desde Guangzhou, la capital de Guangdong, Zheng decidió salir de China rumbo a América en el año 2011, acudió a un intermediario que le consiguió una visa de trabajo. Su plan inicial fue instalarse en Tijuana para posteriormente ingresar a Estados Unidos y reunificarse con sus padres y hermanas que residen en Nueva York. No tenía ningún conocido en México, salvo la red laboral del sector restaurantero de Baja California en Tijuana y Mexicali.

Al ver cerradas sus posibilidades de emigrar legalmente a Estados Unidos y sentirse inconforme con su primer empleo en un restaurante chino, tomó la decisión de moverse al interior de México en busca de mejores ingresos. De Baja California 
se desplazó a Sonora, después se movió a San Luis Potosí y en seguida a Michoacán; entidades en las que se dedicó a trabajar como cajero en restaurantes chinos:

Salí de China porque mi familia está en Estados Unidos. Estando en México es mucho fácil lograr estar con ellos... Vine de Cantón a México con una visa de permiso de trabajador que es poquito difícil, tardé cinco meses... Llegué a México por el aeropuerto de Tijuana porque es único avión que sale directo... Nadie de conocidos aquí. Nadie de ayuda. Primero solicité visa a Estados Unidos, pero embajada rechazó. Entonces busqué trabajo en Mexicali en restaurante chino. Ahí estuve en 2011, tres meses, y luego fui a San Luis Potosí, de cajero de restaurante... Un rato estuve en Michoacán para negocio con un amigo, como tres meses, pero no funcionó... Vengo a D.F. porque un amigo me daba trabajo (entrevista a Zheng, junio de 2015).

A la Ciudad de México llegó en el año 2013. Gracias al periódico chino que se reparte entre la comunidad, se enteró de la existencia de la Iglesia Cristiana China de México. Esa iglesia fue la primera red fuerte a la que pudo pertenecer y gracias a ella dar un giro a su ocupación en un empleo más acorde con su calificación y nivel de instrucción escolar (estudios universitarios). En 2018 se dedicaba a la importación de productos, principalmente juguetes fabricados en China, y era también administrador de una sucursal en ese giro comercial.

A pesar de tener la intención de ser sólo un migrante temporal en México, Zheng decidió quedarse en el país cuando consiguió un mejor empleo, a la par que sus redes sociales comenzaron a ampliarse, y su aspiración inicial de obtener una residencia estadounidense se vio frustrada. La decisión de radicar en México se fortaleció en 2015 cuando contrajo matrimonio con Alba, una joven china de 29 años, y tras el nacimiento del hijo de ambos. Actualmente, los tres viven en la Ciudad de México, y en 2017 pudieron visitar a sus familiares en Nueva York.

El caso de Zheng ejemplifica un tipo de trayectoria, tanto migratoria como laboral, que fue modificándose respecto al proyecto original. En el proyecto migratorio inicial, las redes de parentesco del grupo familiar de origen (progenitores y hermanas) motivaron la movilidad de China a América, pretendiendo utilizar la ciudad de Tijuana como lugar de arribo temporal y puente hacia Estados Unidos. Sus estudios universitarios, un buen manejo de idiomas y su condición urbana facilitaron la movilidad de Zheng al interior de México, apoyada por exiguas redes de amigos. 
Tres acontecimientos marcaron el cambio de rumbo respecto al plan migratorio y laboral originales: la dificultad para ingresar a Estados Unidos, destino inicialmente pretendido; la identificación de una red coétnica consolidada (conformada por un grupo religioso) y su plena incorporación a la misma, lo cual le permitió obtener un empleo más satisfactorio y acorde con sus aspiraciones, y el establecimiento de su propia familia en México derivada del matrimonio y la paternidad.

\section{Trayectoria laboral y migratoria flexible orientada} por redes empresariales

Originario de Wuhan, Hubei, Simón estudió Ingeniería Eléctrica y Automatización en la Universidad de Correos y Telecomunicaciones de Nanjing —centro universitario que se encuentra bajo la jurisdicción directa del Ministerio de Industria y Tecnología de la Información de China.

En una feria de empleo organizada por la misma Universidad y por un grupo de empresas, se enteró de diversas ofertas laborales en el extranjero. Su «espíritu de trotamundos» lo llevó a decantarse por América Latina y pensó que México era un buen destino, particularmente por su cercanía con Estados Unidos.

Firmó su contrato de trabajo en China y la empresa de telecomunicaciones que lo empleó se encargó de gestionar su movilidad al extranjero. En el año 2012 ingresó a México vía Tijuana como punto de escala para llegar a la Ciudad de México, destino en el que vivió un par de años. Los fines de semana pasaba tiempo en el Barrio Chino de la Ciudad de México y dibujaba hànzi en tinta china o iba a la Biblioteca Central de la UNAM a leer. En la entrevista —realizada en idioma inglés - expresó que le gustaba México porque considera que «la vida es más relajada y las personas son muy amables»:

I am an engineer and I work in Bolivar Street. Our clients are TV Azteca television and so on... For me, the life of Mexico is very good, and I like Mexico very much, especially the food and the arts. So far, Spanish is the most difficult thing for me, and I have to learn it well. I met a lot of Mexico people who are very enthusiastic (entrevista a Simón, octubre de 2015).

La emigración internacional de Simón y sus otros compañeros de trabajo también originarios de China, está completamente vinculada a las empresas 
chinas transnacionales. Pertenece a un grupo de migrantes calificados que manejan múltiples idiomas y no tienen inconveniente en moverse alrededor del mundo. De este modo, su estancia en México resultó muy corta, pues consiguió un mejor empleo en Colombia con la empresa Fiberhome (proveedora líder en la fabricación de productos y soluciones en tecnología y telecomunicaciones, así como principal empresa de alta tecnología afiliada directamente a la Comisión de Supervisión y Administración de Activos Estatales del Consejo del Estado chino). Por ello, tuvo que trasladarse a Bogotá en 2014, lugar donde aprende y mejora su español.

En el año 2018, a sus 29 años, Simón estaba realizando un tercer proceso migratorio internacional puesto que Huawei-Dominicana lo contrató como gerente de cuenta. No tiene claro cuánto tiempo estará viviendo en Santo Domingo, pero se siente emocionado por seguir conociendo la región y obtener mejores condiciones laborales.

La trayectoria migratoria y laboral de Simón es muy flexible, similar a la de otros trabajadores globales altamente calificados del siglo XXI, cuyas redes de relaciones sociales no se limitan al parentesco o al paisanaje, sino que están estrechamente vinculadas con su formación profesional y las empresas en que laboran; empresas que se hacen cargo de gestionar lo necesario para su movilidad al exterior de China y alrededor del mundo.

\section{Reflexiones finales}

Las transformaciones económicas y políticas que han llevado a China a convertirse en una potencia mundial, han tenido una fuerte influencia en su movilidad interna e internacional. De acuerdo con varios autores (Van Mol, 2008; Nyíri, 2005; Laczko, 2003), las razones por las que en años recientes se ha incrementado el número de emigrantes chinos en el extranjero están relacionadas con la reestructuración económica, las reformas a las leyes de migración y la integración de China a la OMC. Así, la intensificación de los flujos migratorios internacionales chinos se asocia con factores políticos y económicos que se entretejen para alentar las salidas desde aquel país.

Paralelamente, la inserción de los chinos en las comunidades del exterior va a ser facilitada por redes de relaciones sociales que están produciendo nuevas formas organizativas y que se dan bajo el contexto de la globalización, tanto las 
que establecen los individuos acudiendo a las ventajas que proporcionan las comunicaciones en la era de internet y de la telefonía móvil, como las que generan las grandes empresas transnacionales.

En primera instancia, la investigación realizada permitió observar que la población inmigrante china en México no suele insertarse en el mercado laboral local o en la estructura de oportunidades laborales del destino sino que, gracias al colectivo, tiene la capacidad de generar su propia dinámica de oferta y demanda de trabajo. Las redes sociales étnicas, además, se posicionan como un recurso y un medio primario para el nuevo inmigrante. De igual modo, se convierten en una estrategia para insertarse en el mundo laboral.

El análisis de las trayectorias migratorias y laborales de los nuevos inmigrantes chinos en México, por una parte, permite apreciar la nueva situación y la pujante posición de China en el mundo contemporáneo; por otra, posibilita entender la diversidad de condiciones en las que ocurre la emigración internacional de la población china en la actualidad.

La solidez de las redes familiares y de paisanaje, así como la consolidación de nichos laborales ubicados en servicios estratégicos (en concreto restaurantes étnicos) y en el comercio, continúan proporcionando oportunidades de empleo y sustentando cadenas migratorias tradicionales, reproducidas generacionalmente (como ocurre con Luisa y su familia).

Pero los emigrantes chinos del siglo XXI también provienen de sectores altamente calificados que la economía global demanda a modernas industrias de alta tecnología (high tech) ubicadas en diversos sectores (informática, aeronaútica, telecomunicaciones, entre otras) y en múltiples países. Para estos trabajadores, las redes se extienden del conjunto familiar y del grupo étnico al sector empresarial, y se localizan en diferentes partes del mundo (como ilustra la trayectoria de Simón).

Como ha ocurrido en otros países que han transitado de una economía socialista a una economía de mercado, en China el Estado ha facilitado la salida de sus ciudadanos al extranjero, reformando sus estrictas leyes migratorias. Sin embargo, entre los emigrantes chinos hay notorias diferencias asociadas con las desigualdades económicas y sociales propias del país de origen, que restringen o amplían sus oportunidades en el exterior. Si bien los vínculos familiares y las redes de paisanos pueden apoyar la emigración, las redes empresariales y los vínculos globales marcan diferencias sustantivas en los procesos migratorios y las trayectorias laborales de los individuos. 
En futuras investigaciones será de interés ampliar el estudio de las trayectorias laborales y establecer comparaciones por género, por tamaño de localidad de origen y de destino (rural, urbana o metropolitana), por sector de ocupación y por país o países de residencia.

\section{Referencias}

Acosta Díaz, Félix (2003), «La familia en los estudios de población en América Latina: estado del conocimiento y necesidades de investigación», Papeles de Población, 9(37), pp. 9-50.

Anguiano Roch, Eugenio (2010), «De la Dinastía Qing en el siglo XIX hasta el fin de la República de China», en Historia mínima de China, México, El Colegio de México.

Arango, Joaquín (2003), «La explicación teórica de las migraciones: luz y sombra», Migración y Desarrollo, 1(1), pp. 1-30.

Balán, Jorge, Harley Browning y Elizabeth Jelin (1977), El hombre en una sociedad en desarrollo. Movilidad geográfica y social en Monterrey, México, Fondo de Cultura Económica.

Beltrán, Joaquín (2004), "Remesas y redes familiares desde China a España», en Ángeles Escriva y Natalia Ribas, (coords), Migración y desarrollo. Estudios sobre remesas y otras prácticas transnacionales en España, Córdoba, Consejo Superior de Investigaciones Científicas/Instituto de Estudios Sociales de Andalucía.

Cardiel Marín, Rosario (1997), "La migración china en el norte de Baja California, 18871949», en Ota Mishima (coord.), Destino México. Un estudio de las migraciones asiáticas a México, siglos XIX y XX, México, El Colegio de México.

Instituto Nacional de Estadística, Geografía e Informática (INEGI) (2010), Censo de Población y Vivienda 2010, México, INEGI.

Instituto Nacional de Estadística, Geografía e Informática (INEGI) (2015), Encuesta Intercensal, México, INEGI.

Cinco Basurto, Mónica (2012), "La experiencia de los chinos en México, 1927-1960: racismo, expulsión y repatriación», en Romer Cornejo (coord.), China. Estudios y ensayos en honor a Flora Botton Beja, México, El Colegio de México/Centro de Estudios de Asia y África.

Correa, Gabriela y René Núñez (2013), «Migración y exclusión en China: sistema hukou», Revista Problemas del Desarrollo, 44(172), pp. 105-122. 
Dombois, Rainer (1997), "Relaciones industriales y condiciones laborales», en Anita Weiss (ed.), Modernización industrial: empresas y trabajadores, Bogotá, Universidad Nacional de Colombia.

Farrall, Stephen (2008), «What is qualitative longitudinal research?», Papers in Social Research Methods, Qualitative Series (11), pp. 1-25.

Gandini, Luciana (2015), iEscapando de la crisis? Un estudio comparativo de trayectorias laborales de migrantes argentinos en la Ciudad de México y Madrid, México, Centro Regional de Investigaciones Multidisciplinarias/Universidad Nacional Autónoma de México.

Gómez Izquierdo, Jorge (1991), El movimiento antichino en México (1871-1934). Problemas de racismo y del nacionalismo durante la revolución mexicana. México, Instituto Nacional de Antropología e Historia.

Guofu, Liu (2009), "Changing Chinese migration law: from restriction to relaxation», Int. Migration \& Integration (10), pp. 311-333.

Ham Chande, Roberto (1997), «La migración china hacia México a través del Registro Nacional de Extranjeros», en Ota Mishima (coord.), Destino México: un estudio de las migraciones asiáticas a México, siglos XIX y XX, México, El Colegio de México.

Holland, Janet, Rachel Thomson y Sheila Henderson (2006), «Qualitative longitudinal research: a discussion paper», Working Paper (21), pp. 1-60.

Hu-DeHart, Evelyn (2004), «Inmigrantes a una frontera en desarrollo», en Banco Interamericano de Desarrollo, Cuando Oriente llegó a América. Contribuciones de inmigrantes chinos, japoneses y coreanos, Washington, Banco Interamericano de Desarrollo.

Izraelewicz, Erik (2005), Cuando China cambia el mundo, París, Grasset \& Fasquelle.

Kaplan, David y Wei Li (2006), Landscapes of the ethnic economy, United Kingdom, Rowman \& Littlefield.

Light, Ivan (1972), Ethnic enterprise in Americas: business and welfare among Chinese, Japanese and Blacks, Berkeley, University of California Press.

Liu Hong (2005), «Explaining the dynamics and patterns of Chinese emigration since 1980: a historical and demographic perspective», Journal of Oriental Studies, 39(1), pp. 92-110.

Ma, Laurence J.C. y Carolyn Cartier (2003), The Chinese diaspora: space, place, mobility, and identity, Boston, Rowman \& Littlefield.

Ma Mung, Emmanuel (2000), La diaspora Chinoise, géographie d'une migration, París, Ophrys.

Malgesini, Graciela y Carlos Giménez (2000), Guía de conceptos sobre migraciones, racismo e interculturalidad, Madrid, Catarata. 
Mancini, Fiorella (2013), «El vínculo entre población y trabajo en los estudios laborales de América Latina", en Luciana Gandini y Mauricio Padrón (coords.), Población y trabajo en América Latina: abordajes teórico-metodológicos y tendencias empíricas recientes. Río de Janeiro, Asociación Latinoamericana de Población/Fondo de Población de la Naciones Unidas.

Martínez Montiel, Luz María y Araceli Reynoso Medina (1993), «Inmigración europea y asiática siglos XIX Y XX», en Guillermo Bonfil Batalla (comp.), Simbiosis de culturas. Los inmigrantes y su cultura en México, México, Fondo de Cultura Económica.

Min Zhou y John R. Logan (1989), «Returns on human capital in ethnic enclaves: New York City's Chinatown", American Sociological Review, 54(5), pp. 809-820.

Muñiz Terra, Leticia (2012), "Carreras y trayectorias laborales: una revisión crítica de las principales aproximaciones teóricometodológicas para su abordaje» Revista Latinoamericana de Metodología de las Ciencias Sociales, 2(1), pp. 36-65.

Muñoz, Humberto, Orlandina de Oliveira y Claudio Stern (1977), Migración y desigualdad social en la Ciudad de México, México, Universidad Nacional Autónoma de México.

Nieto, Gladys (2007), La inmigración china en España. Una comunidad ligada a su nación, Madrid, Catarata/Universidad Autónoma de Madrid.

Pacheco, Edith y Mercedes Blanco (2002), «En busca de la metodología mixta, entre un estudio de corte cualitativo y el seguimiento de una cohorte en una encuesta retrospectiva», Estudios Demográficos y Urbanos (51), pp. 485-521.

Pál Nyíri, (2002), "Globalising Chinese migration: new spaces, new meanings», Migracijske i etnike teme, 18(1), pp.23-40.

Pan, Lynn (1999), The encyclopedia of the Chinese overseas, Singapur, Chinese Heritage Centre.

Pieke, Frank N. (2006), "Comunidad e identidad en el nuevo orden migratorio chino», en Antolín Beltrán (ed.), Las diásporas de Asia Oriental en Europa Occidental, Barcelona, CIDOB Ediciones.

Portes, Alejandro y Min Zhou, (2013), «El águila y el dragón: el papel de las organizaciones transnacionales de inmigrantes en China y México", Migración y Desarrollo, 11(20), pp. 106-154.

Portes, Alejandro y Leif Jensen (1989), «The enclave and the entrants: patterns of ethnic enterprise in Miami before and after Mariel», American Sociological Review (54), pp. 411-414.

Puig Llano, Juan (1992), Entre el río Perla y el Nazas, México, Consejo Nacional para la Cultura y las Artes. 
Rivera Sánchez, Liliana (2012), «Las trayectorias en los estudios de migración: una herramienta para el análisis longitudinal cualitativo», en Marina Ariza y Laura Velasco (coords.), Métodos cualitativos y su aplicación empírica: por los caminos de la investigación sobre migración internacional, México, Instituto de Investigaciones Sociales-Universidad Nacional Autónoma de México/El Colegio de la Frontera Norte.

Salazar Anaya, Delia (1996), La población extranjera en México (1895-1990). Un recuento con base en los censos generales de población, México, Instituto Nacional de Antropología e Historia.

Sanders, Jimy y Victor Nee (1987), "On testing the enclave-economy hypothesis. A reply to Portes and Jensen», American Sociological Review (52), pp. 771-773.

Tébar Arjona, Jesús (2013), «Patrones espaciales de la diáspora china en el mundo, España y Madrid», Historia Actual Online (30), pp. 89-103.

Trolliet, Pierre (1994), La diaspora Chinoise, París, PU de France.

Waldinger, Roger (1993), "The ethnic enclave debate revisited», International Journal of Urban and Regional Research, 3(17), pp. 444-452.

Wang Gungwu (1991), China and the overseas Chinese, Singapore, Times Academic Press. Wilson, Kenneth L. y Alejandro Portes (1980), "Immigrant enclaves: an analysis of the labour market experiences of Cubans in Miami», American Joumal of Sociology, 86(2), pp. 295-319.

Xiang Biao (2003), «Emigration from China: a sending country perspective», International Migration, 41(3), pp. 21-48.

(2005), «Relaciones internacionales y migraciones transnacionales: el caso de China», Revista CIDOB d'Afers Internacionals (68), pp. 133-149. (2010), "Labour Pains», India International Centre Quarterly, 36(3/4), pp. 252-263.

Xu Shicheng (2007), "Los chinos a lo largo de la historia de México: las culturas de China y de América Latina», en Enrique Dussel Peters y Yolanda Trápaga (coords.), China y México: implicaciones de una nueva relación, México, La Jornada Ediciones. Zlotnik, Hania (1991), "La migración asiática a Latinoamérica», Estudios de Asia y África, 26(3), pp. 515-533. 